\title{
Cutaneous Nocardiosis
}

\author{
Laura Atzori*, Anna Luisa Pinna and Monica Pau \\ Department of Medical Science, Dermatology Clinic, University of Cagliari, Italy
}

Received: January 06, 2014; Accepted: February 11, 2014; Published: February 14, 2014

*Corresponding author: Laura Atzori, Dermatology Clinic- Department of Medical Science "M.Aresu”, University of Cagliari, Via Ospedale, 54-09124 Cagliari, Italy, Tel: 00390706092324; Fax: 00390706092580; E-mail: atzoril@unica.it

\begin{abstract}
Nocardiosis is a rare infection, potentially severe when the diagnosis is delayed and/or the response to treatment is ineffective because of multidrug resistance. The number of patients suffering from nocardiosis is constantly rising worldwide, and especially the occurrence among immunocompetent patients is a matter of concern. Surgical site infections, although rare, should be considered among risks factors. Skin manifestations are often the first signs of the infection, both for direct inoculum (primary cutaneous infection) or disseminated disease. Clinicians might be misguided from the variable, unspecific, polymorphous skin eruptions, simulating more common diseases. Especially in the immune suppressed patients symptoms might evoke the same disease for which the patient is under treatment. The dermatologist's expertise and high level of suspicion are crucial to settle the extensive differential diagnosis, cooperating with the pathologist, and microbiologist to find out the causative organism. Molecular methods of identification could improve diagnosis and the chances of survival, but are not routinely performed in many laboratories.
\end{abstract}

Keywords: Nocardia infection; Primary cutaneous nocardiosis; Disseminated nocardiosis; Risk factors; Differential diagnosis

\section{Cutaneous Nocardiosis}

Nocardiosis is a rare human infection reported worldwide [1-7] due to ubiquitous soil born gram-positive, filamentous aerobic bacteria, initially confused with fungi although their branching filaments are thinner than true hyphae (1-2 $\mu \mathrm{m}$ vs 3-5 $\mu \mathrm{m}$ in diameter). Nocardia genus shows similarities with other filamentous bacteria (nocardioforms), therefore grouped under the Actinomycetales order [8]. The disease is more frequent in tropical countries, without age or ethnic predilection, although slightly more common in males than females [1,2]. Male predominance is probably related to the type of working and environmental exposure to the infection, rather than to genera differences [9]. In western countries the prevalence is probably underestimated $[4,7,9]$ and last decade increased reporting has changed the common attitude to consider it just an opportunistic infection, with approximately $1 / 3$ of immunocompetent patients affected, and a considerable risk associated with major surgical procedures or trauma [1-9].

First signs are frequently cutaneous, either as part of a systemic infection disseminated to the skin, or as a primary cutaneous inoculation. Primary cutaneous nocardiosis is more common, with incidence rates ranging from $5 \%$ to $24 \%$ in various countries like India, UK, and Spain [10-12]. A major problem is correct identification, as clinical presentation is not peculiar as well as histological findings, suggestive of an infective process, but not able to detect the microorganisms, unless a tissue culture has been performed and Gram stained. The laboratory should be advised of the clinical suspicion, as Nocardia is a slow-growing bacterium, and cultures are often discarded when no growth is seen within 48 hours, or obscured by rapidly growing bacteria [1].

Once the Nocardiosis is presumed, speciation might take 1-3 weeks, and each strain has individual antibiotic susceptibility pattern, conditioning empiric treatment and possible fatal course. Newer molecular technologies promise to provide rapid and accurate identification [13], but first of all have revolutionized taxonomy, and we have to face with currently more than 30 species. Clinical relevance has been determined for about seventeen species $[14,15]$ in respect to the 4 pathogens identified by traditional hydrolysis patterns: $N$. asteroides, $N$. brasiliensis, $N$. otitidiscaviarum, and $N$. transvalensis. Distinct serotypes and biotypes might share the same antibiotic susceptibility profile [8,13-18]. In western Europe and USA, the term "N.asteroides complex" is frequently used, failing to differentiate the strain cluster (N.asteroides sensu strictu) from $N$. cyriacigeorgica, $N$. farcinica, N. nova, N. abscessus, Nocardia brasiliensis, which is the second most common isolates in the majority of countries $[14,16]$, differs from N.pseudobrasiliensis in mycolic acid pattern, adenine decomposition, nitrate reduction, and antimicrobial agent susceptibilities [18] For all these issues, clinical management and treatment of patients with nocardial disease remain a challenge. This review characterizes the cutaneous manifestations and related risk factors, to suggest clues in clinical diagnosis, raise physicians alert to avoid delayed recognition and address the correct assessments.

\section{Skin manifestations}

From a general health perspective, cutaneous nocardiosis (CN) traditionally occurs with 3 main patterns: (1) actinomycetoma, (2) lymphocutaneous (sporotrichoid) infection, (3) superficial skin infection (Table 1). Some classification adds a distinct $4^{\text {th }}$ pattern, corresponding to the secondary skin 
Table 1: Cutaneous nocardiosis: clinical patterns, responsible strains and differential diagnosis.

\begin{tabular}{|c|c|c|c|c|}
\hline & Main species & Differential Diagnosis & Course & Empirical therapy \\
\hline Mycetoma & $\begin{array}{l}\text { N. brasiliensis } \\
\text { N. pseudobrasiliensis }\end{array}$ & $\begin{array}{l}\text { Eumycetoma } \\
\text { Botriomycetoma } \\
\text { Skin malignancies }\end{array}$ & Chronic & $\begin{array}{l}\text { TMP/SMX + } \\
\text { Minocycline }\end{array}$ \\
\hline Lymphocutaneous infection & $\begin{array}{l}\text { N. brasiliensis } \\
\text { N. pseudobrasiliensis } \\
\text { N. abscessus } \\
\text { N. asteroides } \\
\text { N. farcinica } \\
\text { N. nova }\end{array}$ & $\begin{array}{l}\text { Sporotrichosis } \\
\text { Atipycal mycobacteriosis } \\
\text { Other deep fungal infections }\end{array}$ & Subacute & $\begin{array}{l}\text { TMP/SMX } \\
\text { Minocycline; } \\
\text { Amoxicillin-clavulanic acid, } \\
\text { linezolid, ceftriaxone }\end{array}$ \\
\hline $\begin{array}{l}\text { Superficial skin infection / } \\
\text { Secondary dissemination }\end{array}$ & $\begin{array}{l}\text { N. asteroides } \\
\text { N. abscessus } \\
\text { N. farcinica } \\
\text { N. nova } \\
\text { N. asiatica } \\
\text { N. transvalensis } \\
\text { N. otitidiscaviarum }\end{array}$ & $\begin{array}{l}\text { - Other bacterial Infections and } \\
\text { bacteremic lesions } \\
\text { - Inflammatory conditions: } \\
\text { Erythema nodosum; pyoderma } \\
\text { gangrenosum; Sweet syndrome; } \\
\text { other vasculitis } \\
\text { - Skin Metastasis }\end{array}$ & $\begin{array}{l}\text { Acute or } \\
\text { subacute }\end{array}$ & $\begin{array}{l}\text { Very resistant strains: } \\
\text { Amikacin + Imipenem/ } \\
\text { meropenem, Linezolide }\end{array}$ \\
\hline
\end{tabular}

infection, due to dissemination from a pulmonary disease [19]. Besides, there are not unique distinctive elements allowing the clinical differentiation of a primary superficial skin infection from a secondary dissemination. From our experience, the severity, number or distribution of the lesions are not directly evocative of the general state of the patient, as internal organs infection might present with isolate quite indolent subcutaneous nodules (Figure 1), while by converse, very severe diffuse lesions, accompanied with fever and general malaise in other patients were not due to an hematogenous spread (Figure 2). Dissemination to the skin is estimated to occur in approximately $20 \%$ of patients with systemic nocardial infection [3] Chronic or underestimated skin infection might be at any moment complicated by dissemination to the internal organs $[1,8,19]$ although an estimation of such risk is not currently reported. Thus, any skin manifestation suspect for nocardial infection requires a complete assessment for internal organs involvement.

Actinomycetoma is also called Madura Foot after the Indian region were the disease was firstly described in 1842 [20]. It is the most frequent presentation in tropical countries, especially Mexico, and South America [1,8,21], but it is also sporadically reported in temperate countries [22-24]. The incubation period varies from several weeks to months. Other than the lower extremities, the hands and forearms might be affected. Nocardia mycetoma is clinically indistinguishable from the Eumycetoma type, which is due to fungi, and the Botryomycetoma type, which is due to other bacteria (S. aureus, Pseudomonas Aeruginosa, E.coli, Proteus mirabilis, etc.). Initial lesions might be characterized by quite indolent erythematous tumor-like soft-tissue swelling, in which multiple subcutaneous nodules are palpable, progressively tending to ulcerate, and draining a peculiar purulent material, with pale yellow granules (sulfur grains). The deep infection has a chronic course, with granulomatous and fibrotizing evolution, leading to multiple sinus tracts formation, covered with hypertrophic verrucous skin (Figure 3) and later progressive destruction of subcutaneous tissues, fascia, and muscles, causing deformation and functional impairment. Osteomyelitis is a frequent complication, and plain
X-ray assessment or CT scan is advisable to depict bony osteolytic areas (moth eaten) and eventual periosteal reaction. The "dotin-circle" sign has recently been proposed as a highly specific early sign of mycetoma on magnetic resonance imaging (MRI) $[25,26]$, consisting of multiple small cystic subcutaneous areas with central hypointensity dots. The sign has been applied also to ultrasonography (USG), -where the circle areas are hypoechoiec with central hyperechoiec foci [27]. Morbidity is significant, with persistence over years, and even incurable cases, leading to wide ablative surgical intervention or final amputation [28].

Lymphocutaneous nocardiosis is the most unusual form $[29,30]$ or probably underestimated for the similarity with sporotrichosis, a more common deep fungal infection characteristically spreading along lymphatics after a skin injury. A certain predilection for children has been noted [31,32]. Lower

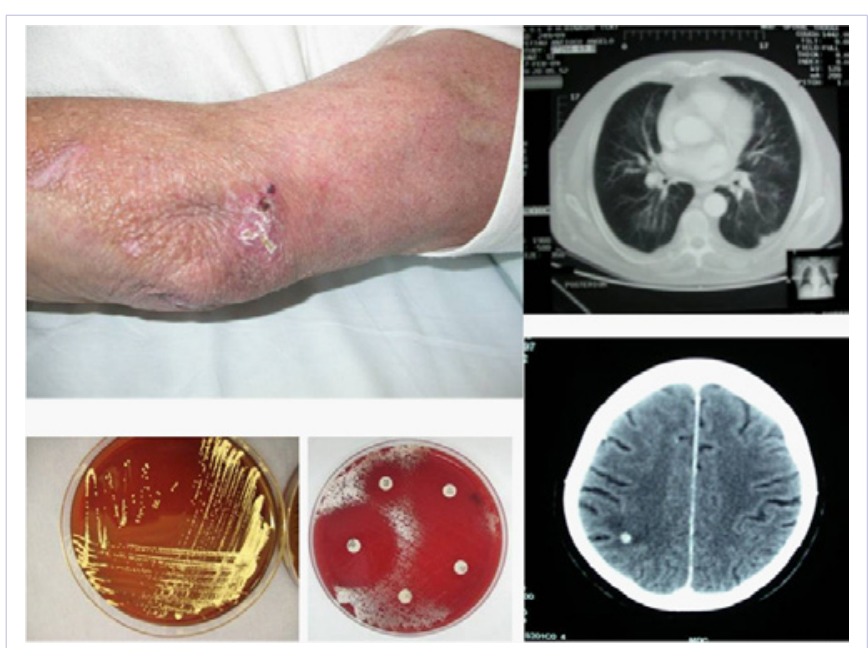

Figure 1: A painless erythematous swollen patch with few hemorrhagic vesicles and crusting on the left elbow of a 65 year-old white man, under high doses corticosteroid therapy for a recent diagnosis of Pemphigus vulgaris. Laboratory culture from the skin specimens allowed identification of Nocardia colonies, further identified by PCR as $N$. asteroides. Radiologic imaging assessed the presence of a pulmonary and brain involvement. 
extremities are more affected, but hands follow, especially in patients with a history of gardening or thorn injuries, preceding of several days the eruption onset (Figure 4). Sometimes the port of entry is hardly detectable, otherwise affected with a swollen erythematous excoriation or ulcer, but the attention is attracted from the multiple erythematous painful nodules or satellite pustules linearly distributed on the main veins and lymphatics, proximally moving with lymphangitis striae towards the regional lymph nodes. The course is subacute, usually requiring long-term antibiotic therapy (2-6 months), and possible relapses.

Superficial skin infection is a very polymorphous pattern, wide spread erythematous papules and pustules (Figure $2 \& 5$ ), sometimes bullae, mixed with subcutaneous nodules similar to erythema nodosum, but less painful. All these elements (multiple mycetomas) might produce abscesses and ulcers, discharging variable content of pus, necrotic and hemorrhagic materials (Figure 2). Multiple lesions might appear on an erythematous edematous plaque, with ill-defined borders resembling cellulitis

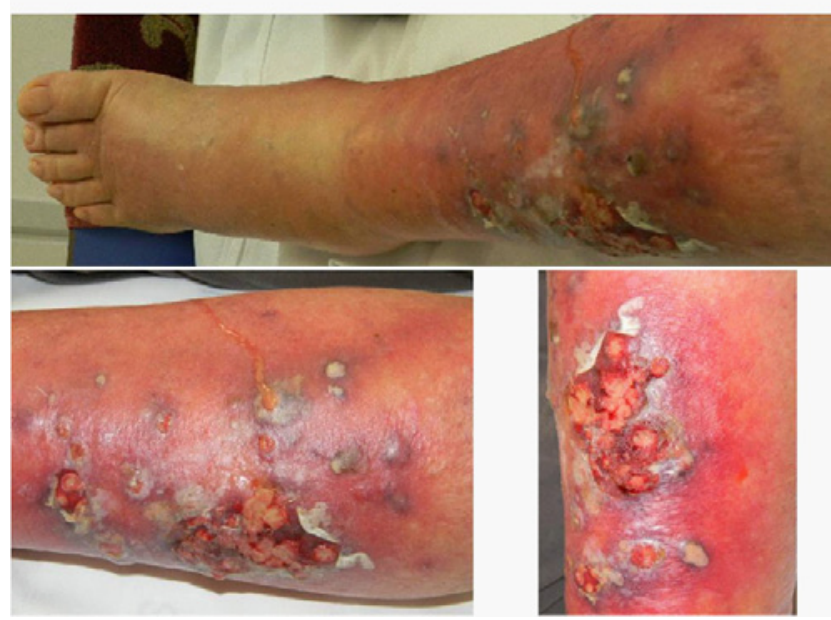

Figure 2: A severe cellulitis of the left leg, extending on the foot and ankle, with erythematous haemorragic papules and pustules draining pus and sero-haematic material, subcutaneous nodules, necrotic ulcers. The 58 year-old white man was otherwise healthy, with a history of minor trauma while gathering wood 2 weeks before the eruption onset. Cultures from the skin specimens allowed identification of Nocardia colonies, further identified by PCR as $N$. brasiliensis. Any systemic involvement was excluded.

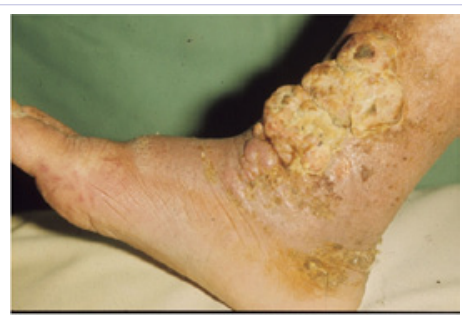

Figure 3: Madura foot in a 65 year-old white man, working as farmer with a history of venous insufficiency and chronic lymphoedema, but not reporting a specific trauma history. Although susceptible to conventional antibiotic therapy, the coalescent hypertrophic nodules of the ankle required repeated surgical interventions.

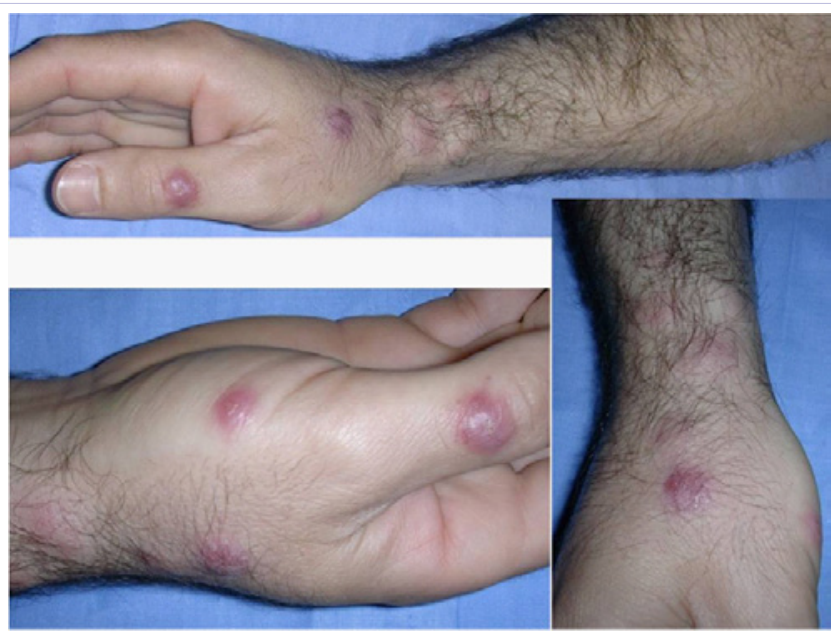

Figure 4: A lymphocutaneous nocardiosis in a 26 year-old white healthy gardener, with a history of rose thorn injury several weeks before the eruption onset. Tissue cultures from a skin biopsy suggested the Nocardia responsibility, and further laboratory identification isolates $N$. asteroides.

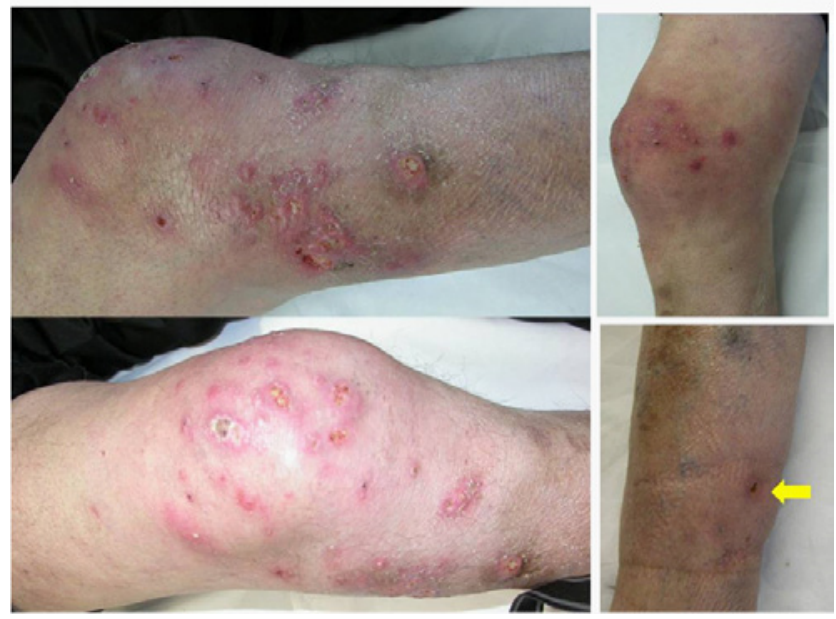

Figure 5: Superficial skin nocardiosis of the right leg and knee in a 66 year-old white man, under low doses corticosteroids for chronic rheumatoid arthritis. A minimal port of entry was noted (yellow arrow) where the patient referred an insect bite. The central hospital laboratory identified $N$. asteroides from the skin cultures, but optimal response to amoxicillin-clavulanic acid might suggest $N$. abscessus responsibility. Molecular methods were not available at that time.

[33]. Extremities are most commonly affected, and unilateral distribution might be suspicious of a primary cutaneous exposure, but solitary lesions on different body sites are also reported in cases in which a systemic disease has been accurately excluded [34]. Manifestations mimic more common infection, such as Streptoccoccus or Staphylococcus species, and antibiotic empirical treatment might be efficacious in most of the cases. Cultures are not always performed in daily practice, because time and money consuming, until the patient worsens, and complete assessment are performed. A study realized in Texan children documented the occurrence of Nocardia brasiliensis in cellulites or abscess cases 
not improving with appropriate antibiotics [32]. Another crucial point is differential diagnosis from not infective conditions, such as erythema nodosum, pyoderma gangrenosum, and other type of vasculitis, especially in patients under immunosuppressive treatment for autoimmune diseases, such as lupus erythematosus or Crohn's disease, primarily evoking or associated with similar skin manifestations [33-37]. Subcutaneous nodules occurrence have been suspected for pulmonary cancer metastasis in a patient with chronic myelogenous leukaemia [38].

The course of superficial skin nocardiosis is variable, being considered the least serious form of nocardiosis [13], although worsening or relapsing despite adequate management is common. A fatal outcome occurs exclusively in disseminated nocardiosis, especially when $N$. farcinica is implicated $[2,5,38,39]$.

\section{Source of infection and risks factors}

Nocardial natural habitat is the soil, as part of the normal microflora, and therefore the different species with geographical variations might be present in dust, sand, decomposing plant material, but also associated with water, including swimming pool [8]. Especially warm windy conditions might facilitate air dispersal of the microorganisms. Animals such cattle and dogs might be affected [40], but transmission to humans is unusual, as well as inter-human infection. Nosocomial outbreaks have been reported, most frequently in immunocompromised, but also immunocompetent patients intra-operatively exposed to $N$. farcinica. Contamination of arterial stent, prosthesis, or heart/ liver transplantation units transmission via health care workers has been documented, posing the question of intensified handwashing regimen, correct barriers use (gloves, gowns), and environment cleaning $[41,42]$. Some species are more associated with distinct type of human infections, thus the modality of infection and risk factors might be different, considering if the skin has been directly contaminated or by the blood stream dissemination. Several Authors report that primary cutaneous nocardiosis is more common than disseminated infection $[10,19,21]$, but large general hospital studies are usually dedicated to systemic nocardiosis, in which skin involvement is only partially considered [2-5].

Direct inoculation to the skin (Primary cutaneous nocardiosis) involves both compromised hosts and immunocompetent individuals, with a history of trauma. It is most commonly caused by Nocardia brasiliensis [10,21,29,43,44], but any of the pathogenetic nocardiae are able to infect the skin, including recently described entities, such as $N$. nova and N.asiatica $[16,17,45,46]$. More aggressive cases are related to N.farcinica and N.Pseudobrasiliensis infections [1,18,28,34]. Considering their ubiquitous distribution, it is plausible that the Nocardia infection has a self-limited course in the majority of cases. Neutrophils are early involved during infection, limiting the spread, but are not able to kill the Nocardia, whose filaments inhibit phagosome-lysosome fusion, and resist the oxidative killing mechanism of phagocytes. Thus, activation of macrophage and cytotoxic $\mathrm{T}$ lymphocyte intervention is necessary to effectively clear the intracellular pathogens, while humoral immunity has a less defined role. The host-parasite relationship and virulence determinants have been magisterially described by Beaman and Beaman [9].

Considering the necessity of a port of entry, main risks factors are:

i. Puncture or other contaminated traumatic inoculum, such as thorn, insect or animal bite, scratch, bullet injury, intravenous drug abuse $[9,19,47,48]$. Occupation like farmer, shepherd, gardener, and an history of rural background or barefoot walking may help in typical pedal mycetoma, but unusual site are also to be considered, such as the face, neck, breast, back or even the scalp, after a car incident, and the vulva simulating an advanced carcinoma [31,49-52].

ii. Diabetes, malnutrition, alcohol abuse are predisposing conditions, as in any kind of infections.

iii. Several studies have documented that steroids administration is the main independent risk factor for development of Nocardia infection [2,53]. Corticosteroid use associated with nocardial disease has been reported in several autoimmune disease and inflammatory conditions (lupus erythematosus, Crohn's disease, autoimmune blistering diseases, sarcoidosis, etc.) [3537,54-57].

iv. Infection at site of surgery is increasingly reported, from biopsy to major procedures, such as open heart sternotomy, vascular prosthesis and central venous catheters insertion $[41,42,58,59]$. Severe postoperative wound infections are conditioned by the virulence of the strain, but also affinity to medical material, and resistance to common antibiotic prophylactic regimen. Further dissemination is common, but appears to have a more benign course in respect to the dissemination phase of a systemic nocardiosis [13].

Blood stream dissemination to the skin usually results from pulmonary disease, caused by direct inhalation of contaminated particles from soil or water, and development of a rather asymptomatic focal pneumonitis, frequently undervalued until secondary symptoms occurrence [1]. Nocardia bacteriemia is rare, although related to a high mortality rate $[39,53,60]$. The microorganisms seem to have a predilection for the lung and central nervous system (CSN) involvement [61], followed by the skin tropism, which is estimated to occur in approximately 10$20 \%$ of patients $[1,2]$. Disseminated nocardiosis typically affects immunocompromised patients, with underlying HIV infection, malignancies, chronic lung disease, solid-organ transplants or previous long-term use of corticosteroids, configuring an opportunistic infection $[3,15,53,62,63]$. Incidence in these high risk patients is $140-340$ folds higher than in the general population [64]. Less than $10 \%$ of patients with disseminated nocardiosis have no identified underlying predisposing factors [15]. The main isolated strain worldwide is Nocardia asteroides, which is part of an heterogeneous taxon following the new 
classification [1,13]. Major case collection in Italy have been studied by a hospitals collaborative network of 11 cities [7], confirming prevalence of Nocardia asteroids sensu strictu, followed by $N$. farcinica, N. nova, and N. brasiliensis. By converse, in Belgium, and Germany the N.farcinica isolate has emerged as the predominant pathogen $[65,66]$, and a review of reported Asian, European, Nord American cases suggest that this isolate occur more frequently than previously recognized [67], showing a more virulent behavior and resistance to several antibiotics (cefotaxime, cefamandole, tobramycin). Another 17- 20\% of isolates under the N.asteoides complex is due to N. nova, firstly characterized by Tsukamura, and responsible of the same spectrum of clinical manifestations, but unique susceptibility to ampicillin and erythromycin $[67,68]$.

\section{Diagnosis}

Nocardiosis is a complex diagnosis, because conventional microscopy and culture have current limitations, and molecular methods are not routinely disposable in daily practice. Dermatologist's high index of suspicion is mandatory to alert the pathologist, microbiologist and other clinicians involved in the assessment. Several specimens should be taken from the skin lesions, because often cultures result negative, although a single nocardial colony is highly indicative, being not usual laboratory contaminants. Skin biopsy for histopathology is necessary to exclude other inflammatory conditions and orient towards an infective process, characterized by a mix middle and deep dermis infiltrate, with abundant neutrophils, nuclear dust and abscesses formation. Focal extension into the subcutaneous fat is frequent. Old mycetoma lesions might be more specific, with palisading histiocytes surrounding the neutrophilic infiltrate and the characteristic grains. Several special stains are used to complete conventional hematoxylin and eosin (H\&E) observation without usually detecting the microorganisms (Gram; Periodic acid-Schiff (PAS); Gomori methenamine silver (GMS); Ziehl-Nielsen). The most reliable and sensitive methods of diagnosis remains the tissue culture execution, stained with Gram, showing the Grampositive branching rods [15]. A fast-acid positivity is detectable for the majority of the Nocardia species, but the fuchsin bound is fable and peculiar weak acid decoloration is suggested (modified Kinyoun stain). The property is transient, generally lost in subcultured colonies [1].

Radiological imaging is necessary to exclude an eventual systemic nocardiosis, and to assess the extent of subcutaneous tissues involvement, although conventional radiography is diagnostic in the advanced stages. Clues to early diagnosis (dot-incircle sign) have been suggested for ultrasound echography and magnetic resonance imaging [25-27]. Routine blood cultures are usually negative, while blood haemato-chemistry exams confirm the inflammatory state, with frequent white cells count increase, prominently neutrophilis, serum C-reactive protein, erythrocyte sedimentation rate, and serum protein electrophoresis anomalies. No serodiagnosis is currently available to identify active nocardiosis, nor skin tests to demonstrate delayed cutaneous hypersensitivity [1,9].
Laboratory identification is the final conclusive diagnosis, but is difficult in routine practice. Presumptive identification from cultures follows a long sequence of steps, from microscopic phenothypic morphology, to lysozyme resistance, hydrolysis patterns (casein, tyrosine, xanthine, hypoxanthine), biochemical reactions to several sugars and other carbon substrates; arylsulfatase use; growth patterns at $35^{\circ} \mathrm{C}$ and $45^{\circ} \mathrm{C}$. Practical indications, algorithm and flowcharts have been suggested for laboratory consultation $[15,65]$, but the time frame required to answer clinician's expectations varies from a minimum of 7 days to several weeks. The most rapid and actual recommended tools for Nocardia species identification are the 16S rRNA gene sequencing and PCR (polymerase chain reaction) restriction fragment length polymorphism (RLFP) [13], but few research laboratories dispose of such procedures. The very crucial point is to obtain a reliable antibiotic susceptibility test to guide the treatment adjustment. Predictive susceptibility has been identified for the main pathogen species, with a VI type classification on the base of the drug patterns $[13,17,65]$. Unfortunately, antimicrobials susceptibility tests (AST) for Nocardia species are difficult to realize in common laboratories, and not conclusive standardized, validated procedures have been agreed, especially considering the recently demonstrated heterogeneity of the genus and interregional variability of the isolates $[1,5,8]$. Guidelines for best laboratory practice have been provided [69] but correlation with clinical outcomes has not been systematically performed.

\section{Therapy}

All antimicrobial categories have been used in Nocardia infections, but"gold standard' treatment has notbeenachieved.The association of erytromycin+ampicillin or sulfonamide+ampicillin was among the most used in past decades, but several aggressive strains are resistant to ampicillin. $N$. farcinica, $N$. cyriacigeorgica, N. brasiliensis and Pseudobrasiliensis, N.otitidiscaviarium [13]. Sulfa-containing agents remain the drug of choice, in combination with trimethoprim [1], variously associated with minocycline, amoxicillin-clavulanate, $3^{\text {rd }}$ generation cephalosporins, amikacin, imipenem, fluoroquinolones, linezolid. Ideally, drug selection should be guided from individual antimicrobials susceptibility tests (AST), but laboratory results have long frame time, and empiric therapy is usually administered. The cutaneous pattern of nocardial infections is therefore useful to address the choice (Table 1), following the drug pattern classification [68].

Mycetoma, and lymphocutaneous nocardiosis, which are mainly due to N.brasiliensis, are most frequently treated with the association trimethoprim+sulfamethoxazole(TMP-SMZ), because of historical high susceptibility and clinical efficacy, sometimes despite the in vitro indication of strain resistance [1,47]. Most of the N.asteroides complex isolates are also susceptible, as well as $N$. transvalensis, while N.otitidiscaviarum is resistant both in vitro and in vivo, but is rarely implicated $[8,13,15,17]$. Beside, severely immunocompromised patients for organ transplants or HIVinfection are frequently intolerant to such therapy, developing skin rash to severe hypersensitivity reaction, persistent myelosuppression and increased concomitant drugs toxicity $[1,8]$. Minocycline has excellent in vitro activity, and is usually 
associated with other bactericidal agents, especially TMP-SMZ, for the additional anti-inflammatory activity [70].

Treatment duration is another crucial point, usually extended for several months after complete clinical recover, because of the high numbers of relapses [15]. Antimicrobial resistance might occur in course of initially efficacious treatments, with sudden worsening. Repeated susceptibility testing should be considered, especially in severe or refractory cases.

Superficial skin infection, as well as mycetoma severe or refractory cases might require wide spectrum antibiotics, also considering the possibility that lesions are part of a disseminated nocardiosis, before all assessment have been performed. Animal models and in vitro data attest imipenem and amikacin superior activity compared with TMP-SMZ and also synergistic effects combing the 3 drugs, but parenteral administration requires hospital settings or expensive out-patient facilities, not affordable for long-term treatment. Limited activity in vitro is suggested for fluoroquinolones, although clinical experiences found it successful in long-term combinations regimens $[8,42]$. Thus, clinician's decisions should be guided by the single patient conditions:

i. Mild to moderate infections should initiate with oral TMP-SMZ alone or in association with minocycline. When sulfonamides are contra-indicated, ampicillinclavulanic or fluoroquinolone preparations can be administered. If the clinical response is slow, a parenteral therapy should be considered, but usually at that time individual antimicrobial susceptibility results are ready to consultation.

ii. Very severe patients require parenteral therapy from the very beginning, with a combination of imipemen/ meropenem; amikacin; cephalosporins or linezolide for 3-6 weeks, than switching to oral preparations if improvement or on the basis of AST results.

iii. Treatment failure can occur for sequestered abscesses and persistent fibrotizing soft tissues inflammation, demarcating the mycetomas, and requiring additional drainage or surgical procedures [28]. Secondary or coexistent infections might complicate the course of skin lesions, especially in the compromised hosts [11].

\section{References}

1. Lerner PI (1996) Nocardiosis. Clin Infect Dis 22(6): 891-903.

2. Minero MV, Marin M, Cercenado E, Rabadan PM, Bouza E, et al. (2009) Nocardiosis at the turn of the century. Medicine (Baltimore) 88(4): 250-261.

3. Mootsikapun P Intarapoka B Liawnoraset W (2005) Nocardiosis in Srinagarind Hospital, Thailand: review of 70 cases from 1996-2001. Int J Infect Dis 9(3): 154-158.

4. Boiron P, Provost F, Chevrier G, Dupont B (1992) Review of nocardial infections in France 1987 to 1990. Eur J Clin Microbiol Infect Dis 11(8): 709-714.

5. Baio PPV, Ramos JN, Dos Santos LS, Soriano MF, Ladeira EM, et al (2013) Molecular identification of nocardia isolates from clinical samples and an overview of human nocardiosis in Brazil. PLoS Negl Trop Dis 7(12): e2573.

6. Beaman BL, Burnside J, Edwards B, Causey W (1976) Nocardial infections in the United States, 1972-1974. J Infect Dis 134(3): 286289.

7. Farina C, Boiron P, Ferrari I, Provost F, Goglio A (2001) Report of human nocardiosis in Italy between 1993 and 1997. Eur J Epidemiol 17(11): 1019-1022.

8. Mc Neil MM, Brown JM (1994) The medically important aerobic Actinomycetes: epidemiology and microbiology. Clin Microbiol Rev 7(3): 357-417.

9. Beaman BL, Beaman L (1994) Nocardia species: host-parasite relationships. Clin Microbiol Rev 7(2): 213-264.

10. Inamadar AC, Palit A (2003) Primary cutaneous nocardiosis: a case study and review. Indian J of Dermatol Venerol Leprol 69(6): 386-391.

11. Das S (2001) Cutaneous nocardiosis in east-Delhi. Indian J Med Sci 55(6): 337-339.

12. Pintatdo V, Gomez ME, Forum J, Meseguer MA, Coba J, et al. (2002) Infection with Nocardia species: clinical spectrum of diseases and species distribution in Madrid Spain, 1978-2001. Infection 30(6): 338-340.

13. Brown-Elliott BA, Brown JM, Conville PS, Wallace RJ Jr (2006) Clinical and laboratory features of the Nocardia spp. based on current molecular taxonomy. Clin Microbiol Rev 19(2): 259-282.

14. Kageyama A, Mikami Y (2007) Taxonomy and phylogenetic analysis of infectious Nocardia strains isolated from clinical samples. Nihon Ishinkin Gakkai Zasshi 48(2): 73-78.

15. Saubolle MA, Sussland D (2003) Nocardiosis: Review of clinical and laboratory experience. J Clin Microbiol 41(10): 4497-4501.

16. Kageyama A, Yazawa K, Ishikawa J, Hotta K, Nishimura K, et al. (2004) Nocardial infections in Japan from 1992 to 2001, including the first report of infection by Nocardia transvalensis. Eur J Epidemiol 19(4): 383-389.

17. Wallace RJ Jr, Brown BA, Tsukamura M, Brown JM, Onyi GO (1991) Clinical and laboratory features of Nocardia nova. J Clin Microbiol 29(11): 2407-2411.

18. Wallace RJ Jr, Brown BA, Blacklock Z, Ulrich R, Jost K, et al. (1995) New Nocardia taxon among isolates of Nocardia brasiliensis associated with invasive disease. J Clin Microbiol 33(6): 1528-1533.

19. Kalb RE, Kaplan MH, Grossman ME (1985) Cutaneous nocardiosis. Case reports and review. J Am Acad Dermatol 13(1): 125-133.

20. Magana M (1984) Mycetoma. Int J Dermatol 23(4): 221-236.

21.Lopez-Martinez R, Mendez-Tovar LJ, Bonifaz A, Arenas R, Mayorga J, et al. (2013) Update on the epidemiology of mycetoma in Mexico. A review of 3933 cases. Gac Med Mex 149(5): 586-92.

22. Binazzi M, Papini M (1983) Madura foot by Actinomadura madurae. A further report on an autochthonous Italian case. Mykosen 26(6): 298-304.

23. De Palma L, Marinelli M, Pavan M, Manso E, Ranaldi R (2006) A rare European case of Madura Foot due to actinomycetes. Joint Bone Spine 73(3): 321-324.

24. Rigopoulos D, Mavridou M, Nicolaidou E, Christofidou E, Antoniou C, et al. (2000). Mycetoma due to actinomycetes: a rare entity in Europe. Int J Dermatol 39(7): 557-558. 
25. Parker L, Singh D, Biz C (2009) The dot-in-circle sign in Madura foot. J Foot Ankle Surg 48(6): 690.

26. Jain V, Makwana GE, Bahri N, Mathur MK (2012) The "dot in circle" sign on MRI in maduramycosis: a characteristic finding. J Clin Imaging Sci 2: 66.

27.Sen A, Pillay RS (2011) Case report: Dot-in-circle sign - An MRI and USG sign for "Madura foot”. Indian J Radiol Imaging 21(4): 264-6.

28.Zein HA, Fahal AH, Mahgoub el S, El Hassan TA, Abdel-Rahman ME (2012) Predictors of cure, amputation and follow-up dropout among patients with mycetoma seen at the Mycetoma Research Centre, University of Khartoum, Sudan. Trans R Soc Trop Med Hyg 106(11) 639-44

29. Fukuda H, Saotome A, Usami N, Urushibata O, Mukai H (2008) Lymphocutaneous type of nocardiosis caused by Nocardia brasiliensis: a case report and review of primary cutaneous nocardiosis caused by N. brasiliensis reported in Japan. J Dermatol 35(6): 346-53.

30. Baradkar VP, Mathur M, Kulkarni SD, Kumar S (2008) Sporotrichoid pattern of cutaneous nocardiosis due to Nocardia asteroids. Indian J Pathol Microbiol 51(3): 432-434.

31. Outhred AC, Watts MR, Chen SC, Sorrell TC (2011) Nocardia infections of the face and neck. Curr Infect Dis Rep 13(2): 132-140.

32. Fergie JE, Purcell K (2001) Nocardiosis in south Texas children Pediatr Infect Dis J 20(7): 711-714.

33. George SJ, Rivera AM, Hsu S (2006) Disseminated cutaneous nocardiosis mimicking cellulitis and erythema nodosum. Dermatol Online J 12(7): 13.

34. Seol CA, Sung H, Kim DH, Ji M, Chong YP, et al. (2013) The first Korean case of disseminated mycetoma caused by Nocardia pseudobrasiliensis in a patient on long-term corticosteroid therapy for the treatment of microscopic polyangiitis. Ann Lab Med 33(3): 203-207.

35. Hara H, Wakui F, Ochiai T (2011) Disseminated Nocardia farcinica infection in a patient with systemic lupus erythematosus. J Med Microbiol 60(Pt6): 847-850.

36. Mosel D, Harris L, Fisher E, Olasz E, Wilson B (2013) Disseminated Nocardia infection presenting as hemorrhagic pustules and ecthyma in a woman with systemic lupus erythematosus and antiphospholipid antibody syndrome. J Dermatol Case Rep 7(2): 52-55.

37. Singh SM, Rau NV, Cohen LB, Harris H (2004) Cutaneous nocardiosis complicating management of Crohn's disease with infliximab and prednisone. CMAJ 171(9): 1063-1064.

38. Nenoff P, Kellermann S, Borte G, Horn LC, Ponisch W, et al. (2000) Pulmonary nocardiosis with cutaneous involvement mimicking a metastasizing lung carcinoma in a patient with chronic myelogenous leukaemia. Eur J Dermatol 10(1): 47-51.

39. Budzik JM, Hosseini M, Mackinnon AC Jr, Taxy JB (2012) Disseminated Nocardia farcinica: literature review and fatal outcome in an immunocompetent patient. Surg Infect (Larchmt) 13(3): 163-170.

40. Ribeiro MG, Salerno T, Mattos-Guaraldi AL, Camello TC, Langoni H, et al. (2008) Nocardiosis: an overview and additional report of 28 cases in cattle and dogs. Rev Inst Med Trop Sao Paulo 50(3): 177-185.

41. Rees W, Schuler S, Hummel M, Hempel S, Moller J, et al. (1995) Primary cutaneous Nocardia farcinica infection after heart transplantation: a case report. J Thorac Cardiovasc Surg 109(1): 181-183.

42. Vuotto F, Faure K, Queyre V, Dessein R, Pasquet A, et al. (2011) Vascular nosocomial Nocardia farcinica infection after arterial stenting in an immunocompetent patient. Can J Infect Dis Med Microbiol 22(1): e10-e11.

43. Duran E, Salvo S, Gil J, Cachon R (2010) Primary nocardiosis by Nocardia brasiliensis in Spain. Enferm Infecc Microbiol Clin 28(8): 571-572.

44. Farina C, Andrini L, Bruno G, Sarti M, Tripodi MF, et al. (2007) Nocardia brasiliensis in Italy: a nine-year experience. Scand J Infect Dis 39(1112): 969-974.

45. Shimizu A, Ishikawa O, Nagai Y, Mikami Y, Nishimura K (2001) Primary cutaneous nocardiosis due to Nocardia nova in a healthy woman. Br J Dermatol 145(1): 154-156.

46. Iona E, Giannoni F, Brunori L, de Gennaro M, Mattei R, et al. (2007) Isolation of Nocardia asiatica from cutaneous ulcers of a human immunodeficiency virus-infected patient in Italy. J Clin Microbiol 45(6): 2088-2089.

47. Benes J, Viechova J, Picha D, Horova B, Zatloukal P (2003) Disseminated Nocardia asteroides infection in an immunocompetent woman following an arm injury. Infection 31(2): 112-114.

48. Sabater S, Uso J, Moreno R, Andres J (2009) Nocardia brasiliensis cellulitis in an injection drug user. Enferm Infecc Microbiol Clin 27(9): 551-552.

49. Kapoor S, Khunger N, Jain RK, Dayal S, Mishra S, et al. (2007) Iatrogenic actinomycetoma of neck and back successfully treated with sulphonamides. Clin Exp Dermatol 32(1): 95-96.

50. Simbula L, Meloni GB, Sanna S, Becchere MP, Dessole S, et al. (2013) Breast abscess by nocardia. Breast J 19(1): 112-113.

51. Welsh 0, Morales-Toquero A, Vera-Cabrera L, Vazquez-Martinez O, Gomez-Flores M, et al. (2011) Actinomycetoma of the scalp after a car accident. Int J Dermatol 50(7): 854-857.

52. Gallo A, Bettoni G, Trezzi G, Lalinga V, Frigerio L (2006) Primary vulvar nocardiosis. Obstet Gynecol 108(3 Pt 2): 728-730.

53. Peleg AY, Husain S, Qureshi ZA, Silveira FP, Sarumi M, et al. (2007) Risk factors, clinical characteristics, and outcome of Nocardia infection in organ transplant recipients: a matched case-control study. Clin Infect Dis 44(10): 1307-1314.

54. Baldi BG, Cruz Santana AN, Takagaki T Y (2006) Pulmonary and cutaneous nocardiosis in a patient treated with corticosteroids. J Bras Penumol 32(6): 592-595.

55. Carducci M, Nosotti L, Calcaterra R, Bonifati C, Mussi A, et al. (2007) Early development of disseminated nocardiosis during immunosuppressive treatment for pemphigus vulgaris. Eur J Dermatol 17(4): 346-347

56. Kakurai M, Hiraga T, Yamada T, Usui K, Kiyosawa T, et al. (1999) Subcutaneous nocardial abscesses in a patient with bullous pemphigoid during immunosuppressive therapy: report of a case and review of the Japanese literature. J Dermatol 26(12): 829-833.

57. Hashimoto Y, Hiruma M, Hisamichi K, Mitsuishi K, Mikami Y, et al (2002) Primary cutaneous nocardiosis with multiple, subcutaneous abscesses in a patient with sarcoidosis. J Dermatolog Treat 13(4): 201-203.

58. Wenger PN, Brown JM, McNeil MM, Jarvis WR (1998) Nocardia farcinica sternotomy site infections in patients following open heart surgery. J Infect Dis 178(5): 1539-1543.

59. Forner G, Mengoli C, Fuser R, Scotton PG (2010) Nocardiosis dissemination following transthoracic needle biopsy: two case 
reports. Infez Med 18(2): 115-119.

60. Beaman BL, Beaman L (2000) Nocardia asteroides as an invasive, intracellular pathogen of the brain and lungs. Subcell Biochem 33: 167-197.

61. Hopler W, Laferl H, Szell M, Pongratz P, Brandi I, et al. (2013) Blood culture positive Nocardia asteroides infection: a case report. Wien Med Wochenschr. 163(1-2): 37-39.

62. Marquez-Diaz F, Soto-Ramirez LE, Sifuentes-Osornio J (1998) Nocardiasis in patients with HIV infection. AIDS Patient Care STDS 12(11): 825-832.

63. Fontana I, Gasloli G, Rossi AM, Bornacina C, Dodi F, et al. (2010) Nocardiosis in a kidney-pancreas transplant. J Transplant doi: $10.1155 / 2010 / 573234$.

64. Ambrosioni J, Lew D, Garbino J (2010) Nocardiosis: updated clinical review and experience at a tertiary center. Infection 38(2): 89-97.

65. Wauters G, Avesani V, Charlier J, Janssens M, Vaneechoutte M, et al (2005) Distribution of Nocardia species in clinical samples and their routine rapid identification in the laboratory. J Clin Microbiol 43(6): 2624-2628.

66. Beaman BL, Boiron P, Beaman L, Brownell GH, Schaal K, et al. (1992) Nocardia and nocardiosis. J Med Vet Mycol 1: 317-331.

67. Schiff TA, McNeil MM, Brown JM (1993) Cutaneous Nocardia farcinica infection in a nonimmunocompromised patient: case report and review. Clin Infect Dis 16(6): 756-760.

68. Wallace RJ Jr, Steele LC, Sumter G, Smith JM (1988) Antimicrobial susceptibility patterns of Nocardia asteroides. Antimicrob Agents Chemother 32(12): 1776-1779.

69. Conville PS, Brown-Elliott BA, Wallace RJ Jr, Witebsky FG, Koziol D, et al. (2012) Multisite reproducibility of the broth microdilution method for susceptibility testing of Nocardia species. J Clin Microbiol. 50(4): 1270-1280.

70.Bernier C, Dreno B (2001) Minocycline. Ann Dermatol Venereol 128(5): 627-637. 